\title{
In vitro Differentiation of Adipose-Derived Mesenchymal Stem Cell into Insulin-Producing Cells
}

\author{
Research Article
}

Babiker $\mathrm{NE}^{1}$, Gassoum A², Musa $\mathrm{HH}^{1}$, Hamed ALDeaf $\mathrm{SA}^{2}$, Abdelraheem NE ${ }^{2,3}$, Fadl-Elmula I ${ }^{6}$, Ali El-Sheikh MA ${ }^{4}$, Abdelrahman Arbab M²,

${ }^{1}$ Faculty of Medical Laboratory Sciences, University of Khartoum, Khartoum, Sudan.

${ }^{2}$ National Center of Neurological Sciences, Khartoum, Sudan.

${ }^{3}$ Faculty of Medical Laboratory Sciences, National University, Khartoum, Sudan.

${ }^{4}$ Faculty of Medicine, University of Khartoum, Khartoum, Sudan.

${ }^{5}$ Faculty of Medicine, Department of Surgery, University of Khartoum, Khartoum, Sudan.

${ }^{6}$ Faculty of Medicine, Al Neelain University, Khartoum, Sudan.

\section{Abstract}

Adipose or fatty tissue is similar to bone marrow ontogenetically. Mesenchymal stem cells can be isolated from different types of adipose tissue depots in greater amount than other sources, making them especially suitable for use in regenerative medicine.

Adipose tissue was taken from Sudanese donors; the SVF which contains MSCs was isolated using enzymatic and density centrifugation techniques. The AD-MSCs were differentiated to insulin producing cells using three steps protocol. The therapeutic effect of islet $\beta$-like cells was determined in vivo using diabetics albino Wister rats.

The adherent cells firstly appeared round and spherical in shape, the characteristic shape of MSC was detected after three weeks incubation. The pheno type of these cells showed positives CD34 and CD13 and negatives CD45 and HLADR markers. AD-MSCs were induced into insulin producing cells by a 3-step (15-days) protocol. The differentiated cells were positive for diathizone stain and displayed positive immuno-reactivity to antihuman insulin antibody. Insulin secretion by islet $\beta$-like cells in high glucose concentration medium showed positive result with $>3.5 \mathrm{u} / \mathrm{mlscale}$ reading. The in vivo result of diabetic rats, showed the response in the test group after $24 \mathrm{~h}$, one week later the glucose level decreased from $400 \mathrm{mg} /$ $\mathrm{dl}$ to $96 \mathrm{mg} / \mathrm{dl}(\mathrm{P}=0.021)$, while in the control group the glucose raised up to $600 \mathrm{mg} / \mathrm{dl}$.

The AD-MSCs can be differentiated into islet $\beta$ - like cells in vitro and function as insulin producing cells both in vitro and in vivo, these cells are promising source of stem cells for $\beta$-cells regeneration.

Keywords: Adipose Tissue; Mesenchymal Stem Cell; Islets $\beta$-like Cells; ISCT; L-DMEM; FBS; PBS; HRP; DTZl; ELIZA.

\section{Introduction}

Adipose or fatty tissue is similar to bone marrow ontogenetically derived from the embryonic mesoderm [1]. Its contains stromal vascular fraction (SVFs) including pre-adipocytes fibroblasts, vascular smooth muscle cells, endothelial cells, resident monocytes macrophages lymphocytes and adipose-derived stem cells (ASCs) [2]. Stem cells from adipose tissue are greater than those from other stem cell sources making them especially suitable for use in regenerative medicine [3]. It can be isolated from different types of adipose tissue depots. There are two main types of adipose tissue depots: white and brown adipose tissue, with each performing a distinct biological function. Brown adipose tissue (BAT) is best known for its thermogenic properties. In humans BAT is present in newborn infants and its amount generally decreases with humans age to a point where it is virtually absent in the mature adult. The functions of white adipose tissue (WAT) are to store energy and to provide insulation throughout development. It is present

*Corresponding Author:

Mohamed Abdelrahman Arbab,

Professor, Faculty of Medicine, Department of Surgery, University of Khartoum, Sudan.

Email: mohamedarbab@hotmail.com

Received: December 29, 2017

Accepted: February 10, 2018

Published: February 14, 2018

Citation: Babiker NE, Gassoum A, Musa HH, Hamed ALDeaf SA, Abdelraheem NE, Abdelrahman Arbab M, et al., In vitro Differentiation of Adipose-Derived Mesenchymal Stem Cell into Insulin-Producing Cells. Int J Stem Cell Res Transplant. 6(1), 287-293. doi: http://dx.doi.org/10.19070/2328-3548-1800043

Copyright: Abdelrahman Arbab $\mathbf{M}^{\circ}$ 2018. This is an open-access article distributed under the terms of the Creative Commons Attribution License, which permits unrestricted use, distribution and reproduction in any medium, provided the original author and source are credited. 
in several parts of the body in small depots and can acquire distinct characteristics based on the location of the depot. The stem cell content of individual depots is still unexplored. In particular, the stem cell population in WAT may hold greater differentiation potential and multipotency [4].

Adipose-derived stem cells (ASCs) can be expanded ex vivo in a relatively short period of time and their stemness defined by their potential to proliferate and differentiate, gradually decreases during serial passages [5]. ASCs secrete cytokines, growth factors and bioactive molecules with trophic paracrinem effects in response to local microenvironmental cues, and these factors are likely to mediate the main mechanisms underlying the regenerative and repair potential of these cells. The cultured ASC preparations are heterogeneous and consist of different populations of stem and progenitor cells with self-renewal properties and multipotent differentiation profiles [6]. Two days after plastic adherence, more than $95 \%$ of cells express CD34, co-express mesenchymal (CD10/CD13/CD90) and pericytic markers (CD140a and -b) and are CD31-/CD45 negative [7]. The heterogeneity of ASC preparations may be due to various causes, including inter donor differences in age, body mass index, gender, ethnicity, and disease status [8]. MSCs from older donors show no spindle shaped morphology in culture compared with MSCs from younger donors. Also the brown adipose tissue and white adipose tissue show different capacities with regard to cell proliferation and yield of stem cells. Epigenetic changes affect stem cell growth and cell differentiation potential. Systemic diseases such as diabetes influence the properties of ASCs, because the hyperglycemic diabetic environment may impact aspects of stemness, including the phenotype, morphology, and differentiation potential of ASCs, the potential use of autologous cell therapies in diabetic patients has caused controversy [6]. Recent reports suggested that certain growth factors, such as vascular VEGF, fibroblast growth factor (FGF)-2, FGF-4, FGF-6, FGF-7, FGF-9, FGF-17, transforming growth factor (TGF)-beta1 TGF-beta2, HGF, keratinocyte growth factor, platelet-derived growth factor AA, and IGF-1 regulate the maintenance of ASC stemness. These factors affect a plethora of responses such as angiogenesis, cellular migration, apoptosis, proliferation and differentiation. In particular, the proliferation of ASCs is regulated by paracrine factors such as FGF-2, FGF-4, interleukin (IL)-6 and stromal-derived factor 1, whereas FGF-2, endothelial growth factor, TGF beta and other factors are involved in differentiation [6].

The aim of the present study was to differentiate adipose-derived mesenchymal stem cells in vitro into insulin-producing cells and to determine the therapeutic effect of islet $\beta$-like cells in vivo using experimental animals.

\section{Material and Methods}

This is an experimental study conducted at the National Center for Neurological Sciences (NCNS) Khartoum, Sudan. The adipose tissue was harvested from subcutaneous layer from the abdominal wall of the donor and processed immediately after collection less than $15 \mathrm{~min}$ for stem cell isolation.

\section{Mesenchymal Stem Cell Isolation from Adipose Tissue}

The adipose tissue sample was placed in sterile petri dish, cut into small pieces using surgical blade, washed 5 times, 5 minutes each with phosphate buffer saline (PBS) (Fisher scientific) containing antibiotic (penicillin/streptomycin) (Biowest.co) until the solution appeared clear. Dulbecco modified Eagle medium (DMEM) (Biowest.co) with $1 \mathrm{mg} / \mathrm{ml}$ of collagenase (Gibco) was then added, and incubated for 4 hours at $37^{\circ} \mathrm{C}$, followed by adding $10 \%$ fetal bovine serum (In vitro gen) to neutralize collagenase. The digested fat was transferred into sterile test tube centrifuged at $800 \mathrm{xg}$ for 10 minutes. The floating adipocytes, lipids and liquid were aspirated leaving stromal vascular fraction (SVF) pallet. The pallet was re-suspended in $160 \mathrm{mM} \mathrm{NH} 4 \mathrm{Cl}$ (LOBA Chemie) and incubated for 10 minutes, the suspension was centrifuged at 400xg for 10 minutes and then at $1000 \mathrm{xg}$ for 30 minutes all at room temperature. The cells were then washed twice with PBS and centrifuged at $400 \mathrm{xg}$ for 10 minutes. The cells pallet was then re-suspended in PBS and filtered through $100 \mu \mathrm{M}$ nylon mesh. The filtered cells were centrifuged at 400xg for 10 minutes, re-suspended in $20 \%$ FBS/DMEM and placed in petri dish (Nest Biotechnology.com). The petri dish was incubated at $37^{\circ} \mathrm{C}$ in $5 \% \mathrm{CO}_{2}$ incubator (Memmert) overnight. The culture medium was changed every 3 days until the confluence reaches $80-90 \%$ then the cells were passaged.

\section{Cell Identification}

After cells isolation and culture from adipose tissue the surface antigens of the cells and their immune phenotypes were stained with (PE, PECY5 and FITC) flurochrome coupled with CD13, CD34, CD45 and HLADR and identified by Flow cytometry.

\section{In vitro differentiation of adipose tissue Mesenchymal Stem Cells into insulin-producing cells (IPC): Adipose mesenchy-} mal stem cells were differentiated into insulin-producing cells by 3 -step chemical induction protocol. In step 1 the cells were treated with high glucose Dulbecco modified Eagle medium (H-DMEM; $25 \mathrm{mmol} / \mathrm{L}$ glucose) supplemented with $20 \%$ fetal bovine serum and $1 \mu \mathrm{M}$ of retinoic acid (sigma) then incubated at $37^{\circ} \mathrm{C}, 5 \% \mathrm{CO}_{2}$ for $24 \mathrm{~h}$. The medium was then exchanged to H-DMEM (biowest co) with only $20 \%$ fetal bovine serum for 2 days. In step 2 , the cells were trypsinized and seeded in extracellular matrix (ECM) gel (Gibco) coated well plates. The medium was changed to low glucose Dulbecco modified Eagle medium (L-DMEM), supplemented with $20 \%$ fetal bovine serum, $10 \mathrm{mmol} / \mathrm{L}$ nicotinamide (stem cell technologies) and $20-\mathrm{ng} / \mathrm{mL}$ epidermal growth factor (Thermofisher scientific) for 6 days. In step 3, for the maturation of insulin-producing cells, the low glucose medium was supplemented with $20 \%$ fetal bovine serumand $10 \mathrm{nmol} / \mathrm{L}$ exendin- 4 (TOCRIS) for 6 days. Cellular differentiation was monitored by using the inverted microscope. The islet $\beta$ - like cells clusters were then stained with diathizone stain (DTZ; Sigma), the differentiated cells were incubated with the staining solution which prepared according to manufacture protocol at $37^{\circ} \mathrm{C}$ for 20 minutes and then examined under the inverted microscope (Motic-AE20).

\section{Immuno-cytochemical staining for insulin}

For immune staining, the differentiated cells were fixed with $4 \%$ para formaldehyde (SDFCL) for 15 minutes, then washed with phosphate buffer saline (PBS) (Fisher scientific). Cells were stained using Dakocytomation En Vision+ Dual system -HRP Kit (Dakocytomation) and mouse anti-human insulin antibody (ZYTOMED systems). 
Figure1. Protocol of in vitro differentiation of MSCs to $\beta$-like cells.

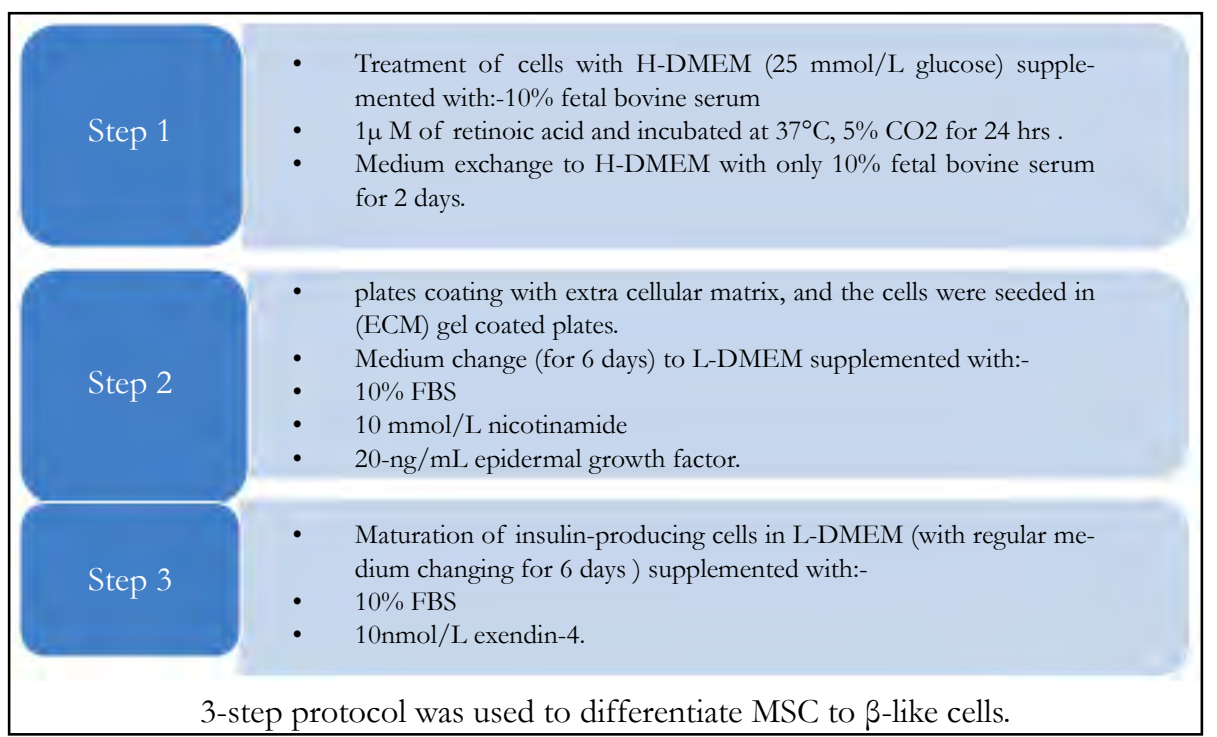

\section{Measurement of spontaneous insulin secretion}

Fifteen days after differentiation, the cells were stimulated by addition of different glucose concentrations $(5.5 \mathrm{mmol} / \mathrm{L}$ and $28 \mathrm{mmol} / \mathrm{L}$ ) into DMEM-LG and incubated for $4 \mathrm{~h}$ at $37^{\circ} \mathrm{C}$ for each concentration respectively. The medium was collected and examined for insulin concentration by using insulin ELIZA kit (Immunospec Corporation) according to the manufacturer protocol.

\section{Laboratory animals experiment}

A total of 8 albino Wister rats, aged 6 to 20 weeks and weighed (165-360g) were obtained from the Experimental Animals Center, Faculty of Veterinary Medicine, University of Khartoum, Sudan. Rats were housed in plastic cages in a room kept at $25^{\circ} \mathrm{C}$ with a 12-h light and dark cycle, and were allowed free access to a commercial pelleted diet and drinking water throughout the experiment. To induce type $1 \mathrm{DM}, 30 \mathrm{mg} / \mathrm{kg}$ of sterptozotocin (STZ) solution in acidified saline ( $\mathrm{pH} 4.5)$ was injected intraperitoneally into the rats on 3 consecutive days. Rats were divided into control group and transplantation group, 4 rats for each group. Three days after STZ induction, the rats in the transplantation group were injected intraperitoneally with $6 \times 10^{6}$ differentiated insulin producing cells suspended in $1 \mathrm{ml}$ of normal saline. While the control group underwent the same procedure, but only injected with normal saline. Blood samples were collected from the tail vein every day, and glucose level in the blood was measured using blood glucose meter (ONE TOUCH, select). The experimental protocol involving the rats was approved in accordance with the guide for the care and use of laboratory animals prepared by the Faculty of Veterinary Medicine, University of Khartoum.

\section{Results}

\section{Adipose Derived Cells}

Under the inverted microscope small size growing cells with plastic adherent characteristics appeared first, the characteristic shape of MSC was detected three weeks later (Figure 2).

\section{Phenotypic characterization of mesenchymal stem cells}

Phenotypic characterization of adipose tissue showed: positive CD34 and CD13 markers (Figure 3, 4) while CD 45 and HLADR cellswere negative (Figure5).

\section{In vitro differentiation of mesenchymal stem cells from adi- pose tissue into insulin-producing cells}

In step 1 no changes in cell morphology, in step 2 decreased proliferation rate, and cell shape became short and turned into round, and in step 3 cluster of islet like cell was formed (Figure 6).

\section{Detection of insulin inside the differentiated cell by Diathi- zone stain}

Diathizone stain results showed red cells as indicator for positive insulin production (Figure7).

\section{Immuno-cytochemical staining for insulin}

The insulin immune staining results showed positive immunoreactivity to anti-human insulin antibody (Figure 8)

\section{Secretion of insulin by insulin- producing cells}

The secretion of insulin analyzed by ELISA showed negative results in the low glucose concentration medium, with 0.00 scale reading, while the high concentration medium showed positive result, with $>3.5 \mathrm{u} / \mathrm{ml}$ scale reading.

\section{Laboratory animals experiment.}

The transplanted groupshowed significant reduction of glucose level compared with control group $(\mathrm{P}>0.021)$ (Figure 8). The results also showed steady decrease of glucose level over time $(\mathrm{P}>0.000)$. The Pearson correlation test proved that age and weight had no effect on glucose level. 
Figure 2. MSCs from Adipose Tissue.

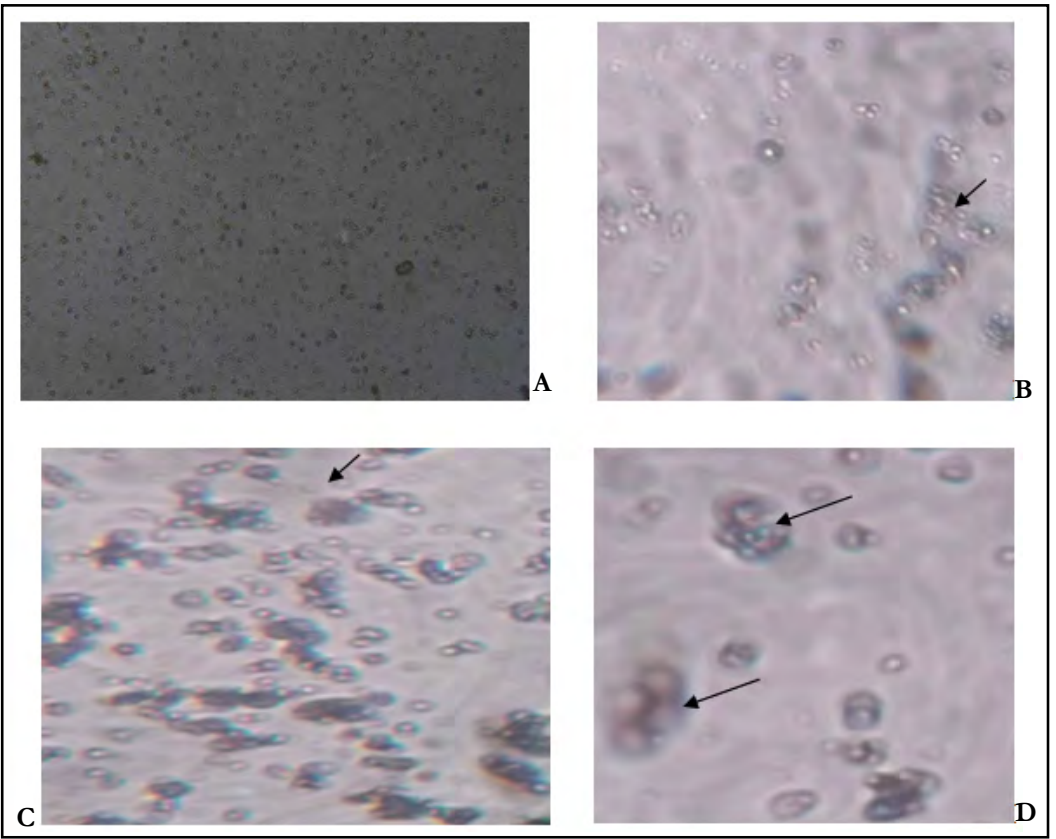

Adipose tissue views: A small size MSCs in P0, B in P1, C in P2 and D P3 MSCs increasing number of cells with occasional colony formation in culture medium. Magnification:A x10, B, C and D x40.

Figure 3. Charactrization of MSCs for CD34

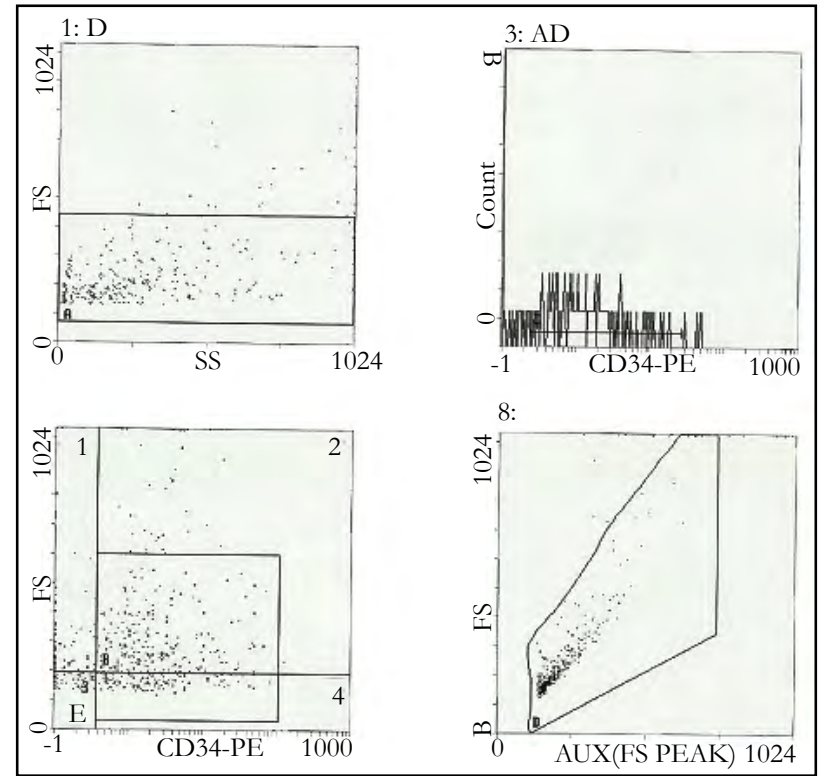

Flow cytometry phenotypic characterization of MSCs from adipose tissue, positive for CD34

\section{Discussion}

The classic sources of stem cells are embryo and bone marrow. Harvesting of these sources are facing either ethical or technical problem. Researchers found adipose tissue as an ideal source of stem cells harvesting [9]. Different methods for isolation of MSC from adipose tissue were used, a commonly enzymatic procession and density centrifugation to isolate the SVF, which contains MSC was reported [10]. In the present study the same technique was used to isolate MSC from adipose tissue. Collagenase was used as digestive enzyme and LDMEM as culture medium, the concentration of FBS was $20 \%$. Bieback et al., reported that the culture conditions could enhance or change properties of MSC if protocols are not standardized. Classical basal culturing media for MSC consists of DMEM or $\alpha$-MEM supplemented with
$10 \%$ to $20 \%$ of fetal bovine serum [11]. Another study reported that when cells were grown in Dulbecco's modified Eagle's medium (DMEM) the isolated ADSC, expanded easily, developed a fibroblast-like morphology and their differentiation capability were more effective [12].

In the present study; the growing cells showed plastic adherent characteristics and appeared very small in size; the characteristic shape of MSC was detected after three weeks in culture. In another study; ADSCs formed clusters of elongated, spindle-shaped (fibroblast-like) MSCs within 3 days and reached cell confluence after one week by using enzymatic digestion to isolate AD-MSCs and cultured the cells in DMEM-F12 [13].

The Mesenchymal and tissue stem cells committee of the Interna- 
Figure 4. Charactrization of MSCs for CD13.

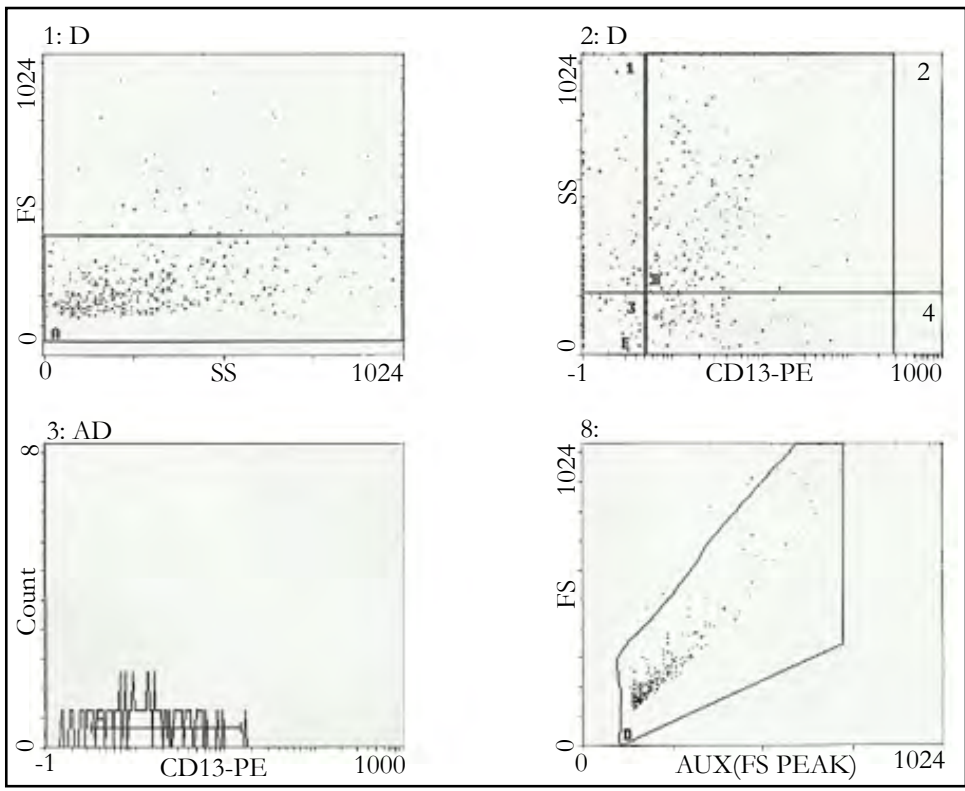

Flow cytometry phenotypic characterization of MSCs from adipose tissue, positive for CD13

Figure 5. Charactrization of MSCs for CD45 and HLA-DR.

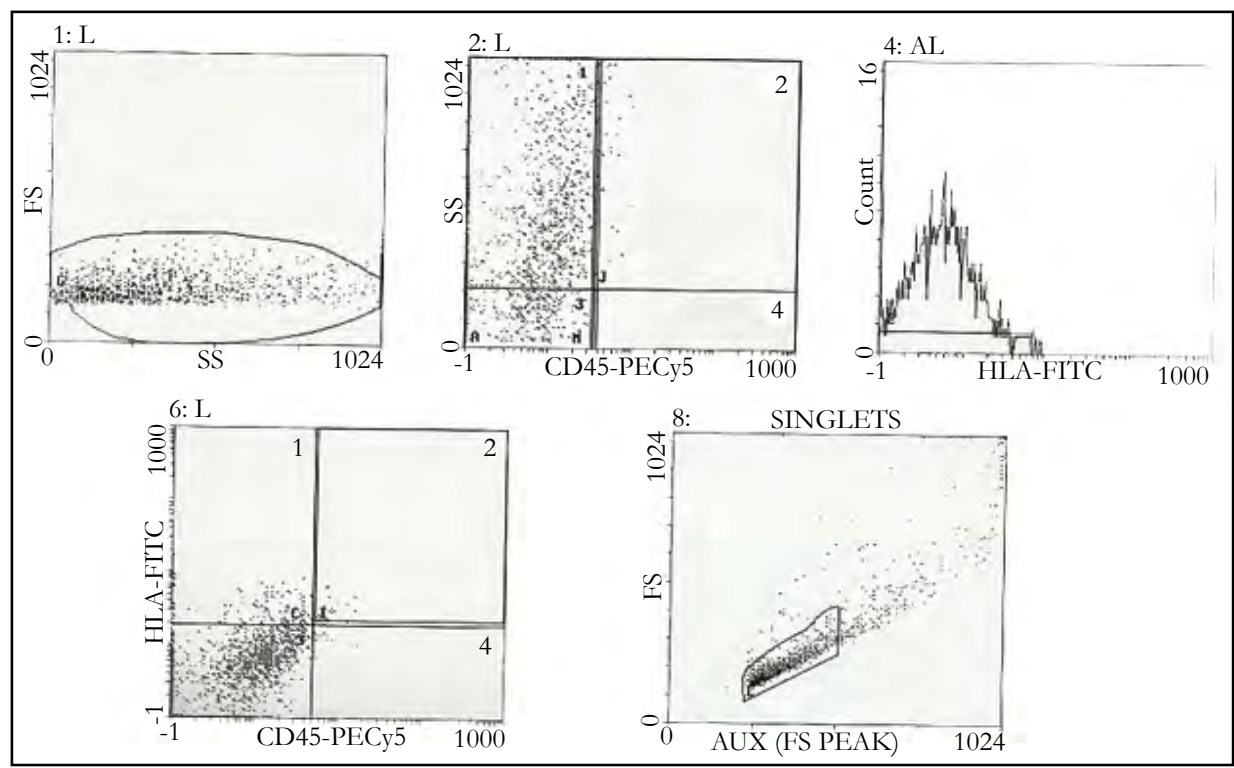

Flow cytometry phenotypic characterization of MSCs from adipose tissue, negative for CD45 and HLA-DR

Figure 6. In Vitro Differentiation of Mesenchymal Stem Cell.
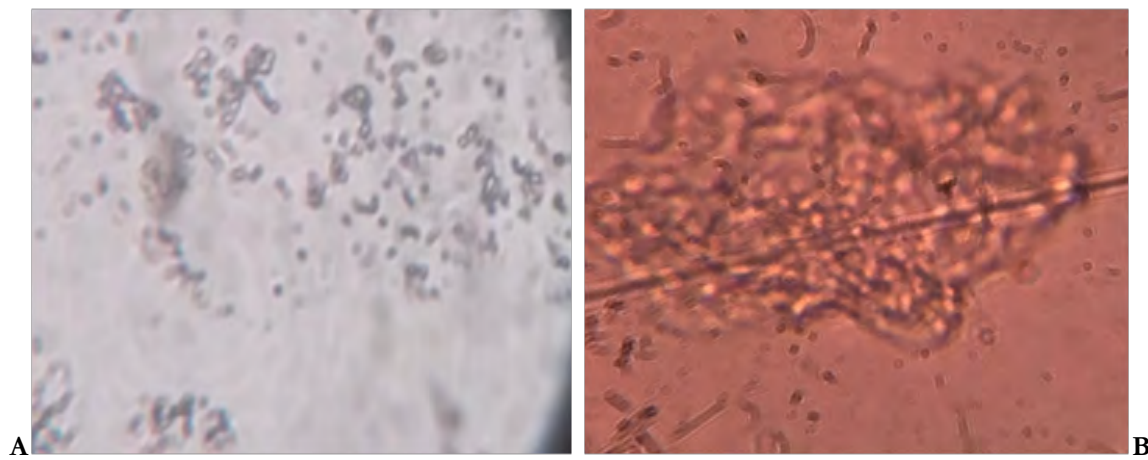

Microscopic photos to AD-MCS differentiation into $\beta$-like cells. A shows differentiated cells in Step2 differentiated protocol, B shows differentiated cell in Step3 differentiated protocol. Magnification x40 
Figure 7. Diathizone stain for insulin producing cells.
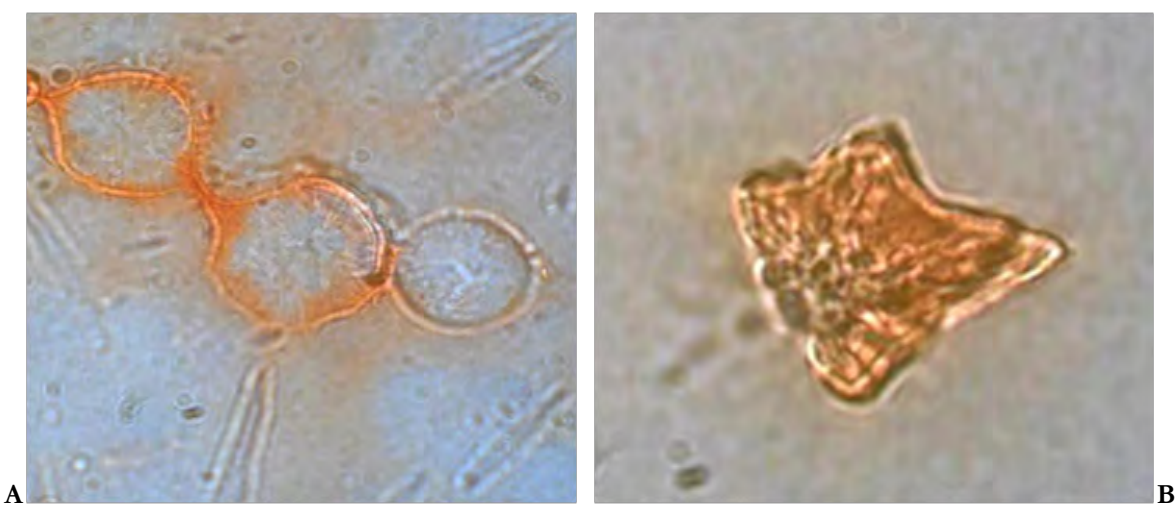

Diathizone stain for insulin producing cells fromAD-MCS, the red color is indicator for positive insulin production. Magnification; A 40X, B x100.

Figure 8. Immuno-reactivity to anti-human insulin Antibody.
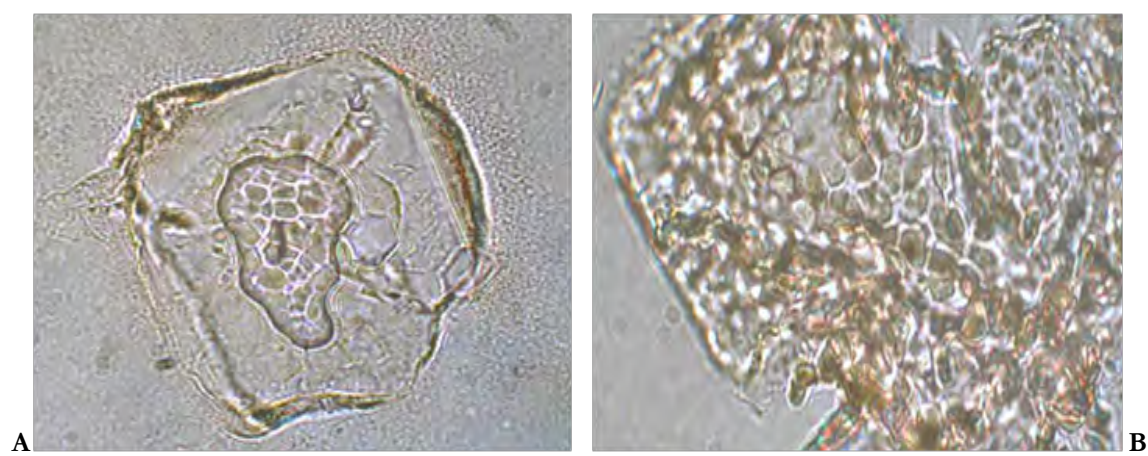

Immuno-reactivity to Anti-human insulin antibody A\&B, AD-MCS. The brown color is indicator for positivity of insulin production. Magnification; A\&B x100.

Figure 9. Glucose levels in rats after transplantation of $\beta$-like cells.

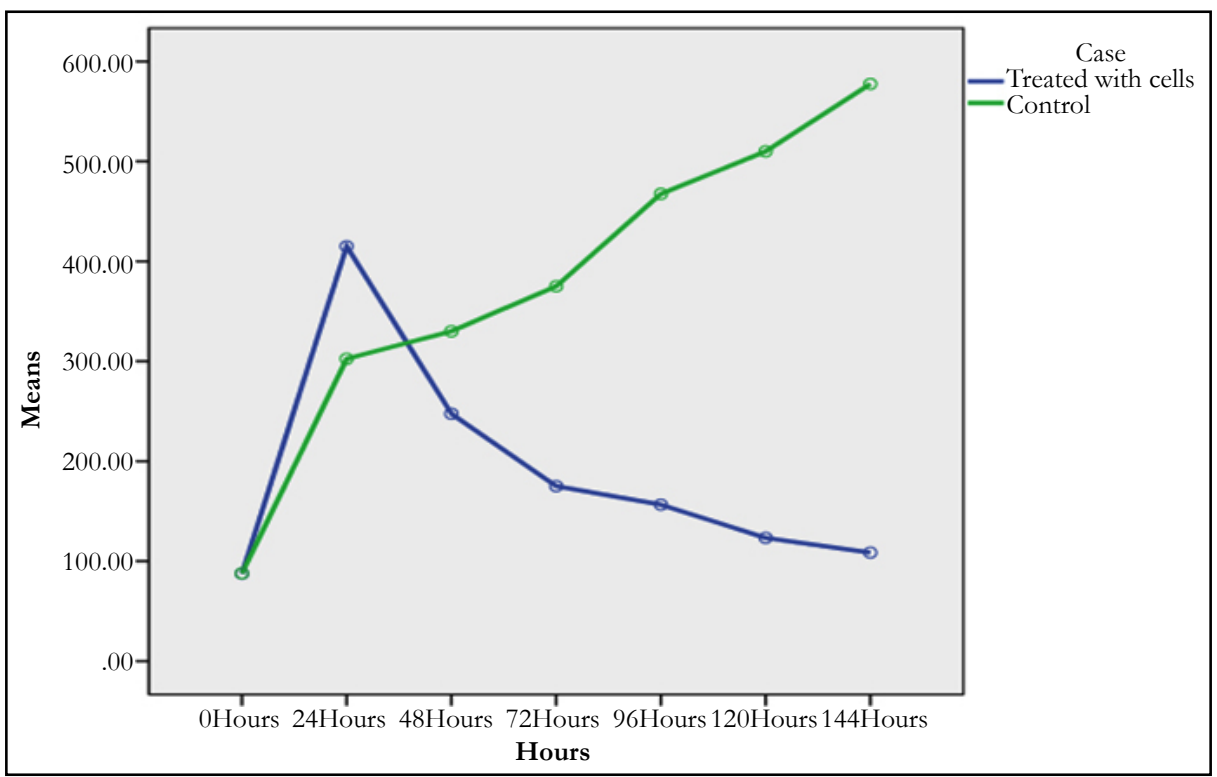

tional Society for Cellular Therapy (ISCT) had proposed minimal criteria to define MSCs including capability to adhere to plastic, specific surface antigen expression and multipotent differentiation potential [14]. Our cell culture showed its capability to adhere to plastic and underwent several passages. Also these cells expressed CD34 and CD13 as positive markers while CD45 and HLADR as negative markers. CD34 marker was reported in ISCT guidelines as specific positive marker for the MSC from the adipose tissue, while CD45, CD14 and HLADR as a negative marker [15].

The cells were capable to differentiate into insulin producing cells by three steps protocol which mimics in vivo pancreatic formation and development. In the differentiation process, the structural changes of cells could be observed and divided to two phases, spheroid cell cluster formation and functional maturation of the islet- like cells [16]. In the present study the morphological chang- 
es appeared in step 2 after the addition of nicotinamide. Nicotinamide, has long been proven to be a potent inducer of endocrine differentiation [17] and used in most differentiation protocols. To obtain insulin-producing cells. Many studies have confirmed that nicotinamide could promote islet $\beta$-cell Proliferation [18]. Cells clusters were formed within 15 days of differentiation, in contrary to the study of Karaoz et al., it took them 38 days to induce the formation of clusters after co-culture with isolated islets [19]. The cells were positive DTZ and showed immuno-reactivity to anti-human insulin antibody and responded to high glucose concentration after 15 days of differentiation, consistent with other studies [20], while in Johnson et al., experiments ADSC differentiated into insulin producing cells and DTZ positive clusters were observed after 30 days [21].

To evaluate the efficacy of IPC therapy in type $1 \mathrm{DM}$ induced rats, the treated group that received the differentiated cells (IPC) showed significant steady reduction of the glucose level compared with the control group. Armita et al., showed significant lower level of glucose when the differentiated cells (IPC) were transplanted to STZ diabetic rats, with significant higher level of insulin. The Improvement of insulin secretion was attributed to the migration of stem cells to the site of damage and promotion of structural and functional repair and thus restoration of the normal insulin level in the body [22].

\section{Conclusions}

The study showed that AD-MSCs can be differentiated into islet $\beta$ - like cells in vitro and function as insulin producing cells both in vitro and in vivo, these cells are promising source of stem cells for $\beta$-cells regeneration. Optimization of methodology seems to yield different results.

\section{Acknowledgment}

This study was conducted at the research laboratory in NCNS. The authors acknowledge the staff of the National Center for Neurological Sciences for their support.

\section{References}

[1]. Zuk PA, Zhu M, Mizuno H, Huang J. Tissue Eng. 2001 Apr;7(2):211-28. PubMed PMID: 11304456.

[2]. Tobita M, Mizuno H. Adipose-derived stem cells and platelet-rich plasma: the keys to functional periodontal tissue engineering. Curr Stem Cell Res Ther. 2013 Sep;8(5):400-6. PubMed PMID: 23957935.

[3]. Mizun H, Tobita M, Uysal AC. Adipose-derived stem cells as a novel tool for future regenerative medicine. Stem Cells. 2012 May;30(5):804-10. PubMed PMID: 22415904.

[4]. Prunet-Marcassus B, Cousin B, Caton D, Andr'e M, P'enicaud L, CasteillaL. From heterogeneity to plasticity in adipose tissues: site-specific differences. Experimental Cell Research. 2006 Apr 1;312(6):727-36. PubMed PMID: 16386732.

[5]. Eom YW, Oh JE, Lee JI, Baik SK, Rhee KJ, Shin HC. The role of growth factors in maintenance of stemness in bone marrow-derived mesenchymal stem cells. Biochem Biophys Res Commun. 2014 Feb 28;445(1):16-22. PubMed PMID: 24491556.

[6]. Tobita M, Tajima S, Mizuno H. Adipose tissue-derived mesenchymal stem cells and platelet-rich plasma: stem cell transplantation methods that enhance stemness. Stem Cell Research \& Therapy. 2015; 6:215. DOI $10.1186 / \mathrm{s} 13287-015-0217-8$.

[7]. Traktuev DO, Merfeld-Clauss S, Li J, Kolonin M, Arap W, PasqualiniR. A population of multipotent CD34-positive adipose stromal cells share pericyte and mesenchymal surface markers, reside in a periendothelial location, and stabilize endothelial networks. Circ Res. 2008 Jan 4;102(1):77-85. Epub 2007 Oct 25. PubMed PMID: 17967785.

[8]. Baer PC, Geiger H. Adipose-derived mesenchymal stromal/stem cells: tissue localization, characterization, and heterogeneity. Stem Cells Int. 2012;2012:812693. doi: 10.1155/2012/812693. Epub 2012 Apr 12. PubMed PMID: 22577397.

[9]. Harsan H, Mariya S, Islam AA, Wahjoepramono EJ, Yusuf I. Isolation of Mesenchymal Stem Cells from Adipose Tissue. Indonesian Biomedical Journal. 2015 Dec 1;7(3):6-153.

[10]. Zuk PA, Ashjian P, Deugat DA, Huang JI, Mizuno H, Alfonso ZC, et al. Human adipose tissue is a source of multipotent stem cell. Mol Biol Cell. 2002 Dec;13(12):4279-95. PubMed PMID: 12475952.

[11]. Bieback K, Kin Zebach S, Karagianni M. Translatingre search into clinical scale manufacturing of mesenchymal stromal cells. Stem cells Int. 2011 Jan 20. doi: $10.4061 / 2010 / 193519$.

[12]. Andreas Sch"Affler, Christa B"Uchler. Adipose tissue-derived stromal cells basic and clinical implications for novel cell based therapies. Stem Cells. 2007 Apr;25(4):818-27. PubMed PMID: 17420225.

[13]. Rebelatto CK, Aguiar AM, Moretão M P, et al. Dissimilar Differentiation of Mesenchymal Stem Cells from Bone Marrow Umbilical Cord Blood and Adipose Tissue. 2008 Jul;233(7):901-13. doi: 10.3181/0712-RM-356. Epub 2008 Apr 29. PubMed PMID: 18445775.

[14]. Dominici M, Le Blanc K, Mueller I, et al., Minimal criteria for defining multipotent mesenchymal stromal cells. Cytotherapy. 2006;8(4):315-7. PubMed PMID: 16923606

[15]. Wankhade UD1, Shen M2, Kolhe R3, Fulzele S4. (2016). Advances in adipose-derived stem cells isolation,characterizationand application in regenerative tissue engineering. Stem Cells Int. 2016;2016:3206807. doi: 10.1155/2016/3206807. Epub 2016 Feb 11. PubMed PMID: 26981130.

[16]. Pokrywczynska M, Krzyzanowska S, Jundzill A, Adamowicz J, Drewa T. (2013). Differentiation of stem cells into insulin-producingcells: current status and challenges. Arch Immunol Ther Exp (Warsz). 2013 Apr;61(2):14958. doi: 10.1007/s00005-012-0213-y. Epub 2013 Jan 3. PubMed PMID: 23283518.

[17]. Otonkoski T, Beattie G M, Mally M I, Ricordi C, Hayek A. Nicotinamide is a potent inducer of endocrine differentiation in cultured human fetal pancreatic cells. J Clin Invest. 1993 Sep; 92(3): 1459-1466. doi: 10.1172/ JCI116723.

[18]. Dave SD1, Vanikar AV, Trivedi HL..(2013). Extrinsic factors promoting in vitro differentiation of insulin-secreting cells from humanadipose tissue-derivedmesenchymal stem cells. Appl Biochem Biotechnol. 2013 Jun;170(4):962-71. doi: 10.1007/s12010-013-0250-y. Epub 2013 Apr 30. PubMed PMID: 23633267.

[19]. Karaoz E1, Okcu A, Ünal ZS, Subasi C, Saglam O, Duruksu G. Adipose tissue-derived mesenchymal stromal cells efficiently differentiate into insulin-producing cells in pancreatic islet microenvironment both in vitro and in vivo. Cytotherapy. 2013 May;15(5):557-70. doi: 10.1016/j. jcyt.2013.01.005. Epub 2013 Feb 4. PubMed PMID: 23388582.

[20]. Dang LT, Bui AN, Pham VM, Phan NK, Van Pham P. Production of isletlike insulin-producing cell clusters in vitro from adipose-derived stem cells. Biomedical Research and Therapy. 2015 Jan 30;2(1):184-92.

[21]. Johnson JD1, Ao Z, Ao P, Li H, Dai LJ, He Z, et al., Different Effects of FK506, Rapamycin and Mycophenolate Mofetil on Glucose-Stimulated Insulin Release and Apoptosis in Human Islets. Cell Transplant. 2009;18(8):833-45. doi: 10.3727/096368909X471198. Epub 2009 Apr 10. PubMed PMID: 19500470.

[22]. Armita Mahdavi Gorabi, FarhadSouri, Mona Jahandideh Kazempor. Mesenchymal Stem Cells (M.S.C.) Effect in Streptozotocin (STZ) Induced Type I Diabetic Rats. The Caspian Sea Journal. 10:91-95. 